\title{
Carcinosarcoma vesical gigante
}

Hernández Cañas V, Álvarez Ardura M, De la Morena Gallego JM, De la Peña Zarzuelo E,

Dominguez Franjo P, Llorente Abarca C.

Servicios de Urología y Anatomía Patológica. Fundación Hospital de Alcorcón. Alcorcon. Madrid.

Actas Urol Esp 2006; 30 (6): 645

$\mathrm{M}$ ujer de 56 años, fumadora, que acude a urgencias por presentar hematuria de dos meses de evolución. Al tacto vaginal se observa útero en anteversoflexión y masa de consistencia dura y dolorosa a la palpación.

Se realiza ecografía donde se aprecia una masa heterogénea ecogénica sugestiva de neoformación vesical, que mide 91,7 x 83,3 mm (Fig. 1).

Se completa el estudio con TAC donde se observa una ocupación prácticamente total de la vejiga por una masa heterogénea de $9 \mathrm{~cm}$, con probable base de implantación en la pared posterolateral derecha (Fig. 2).

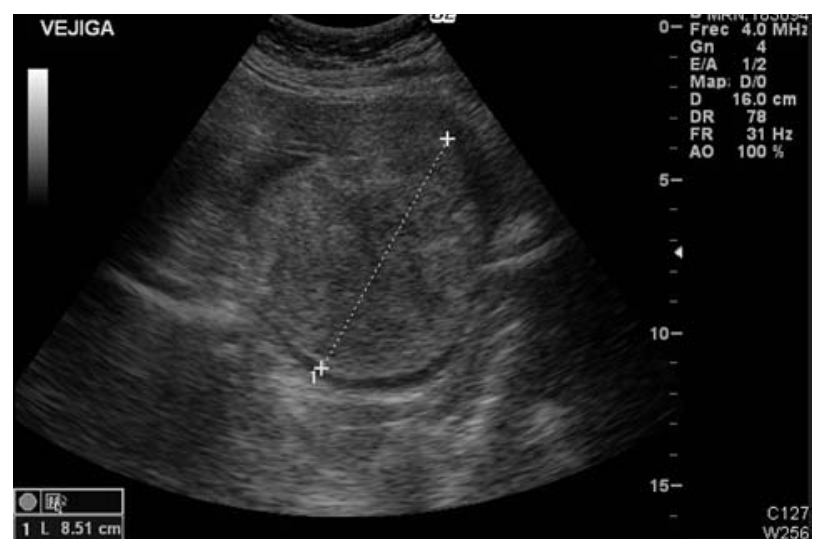

FIGURA 1

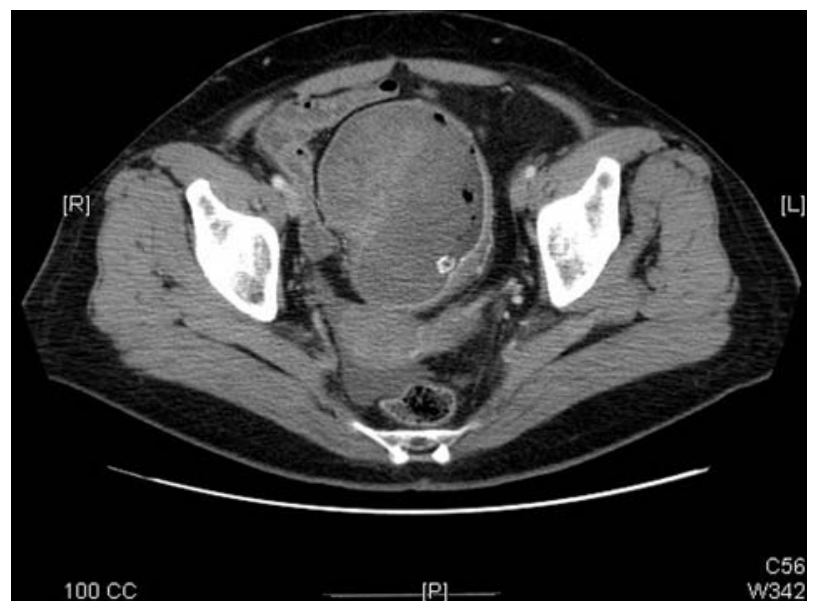

FIGURA 2
Tras la RTU vesical, los hallazgos anatomopatológicos fueron carcinosarcoma. Se realizó exanteración pélvica anterior (Figs. 3 y 4) con linfadenectomía y derivación urinaria tipo Bricker.

La anatomía patológica definitiva fue de carcinoma vesical pT2bNO.

Dr. M. Álvarez Ardura

Servicio de Urología. Fundación Hospital Alcorcón

Budapest, 1

28922 Alcorcón (Madrid)

e-mail: malvareza@fhalcorcon.es

(Trabajo recibido el 14 de julio 2005)

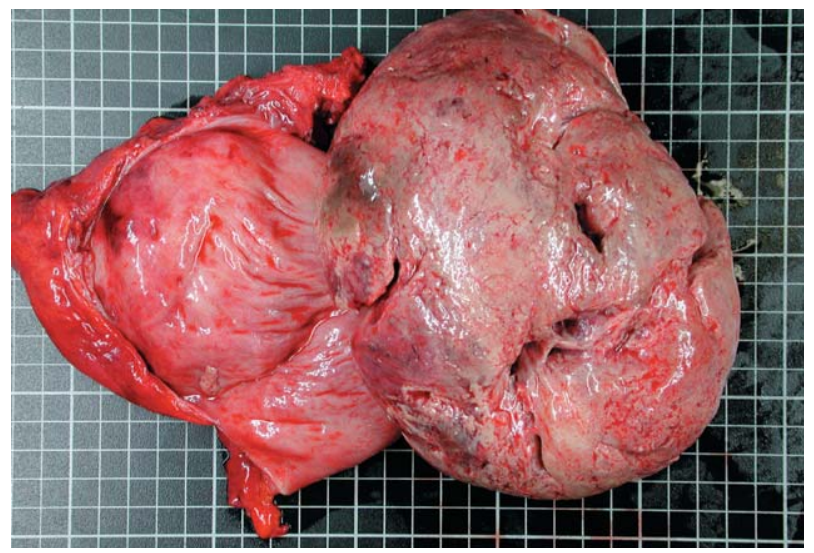

FIGURA 3

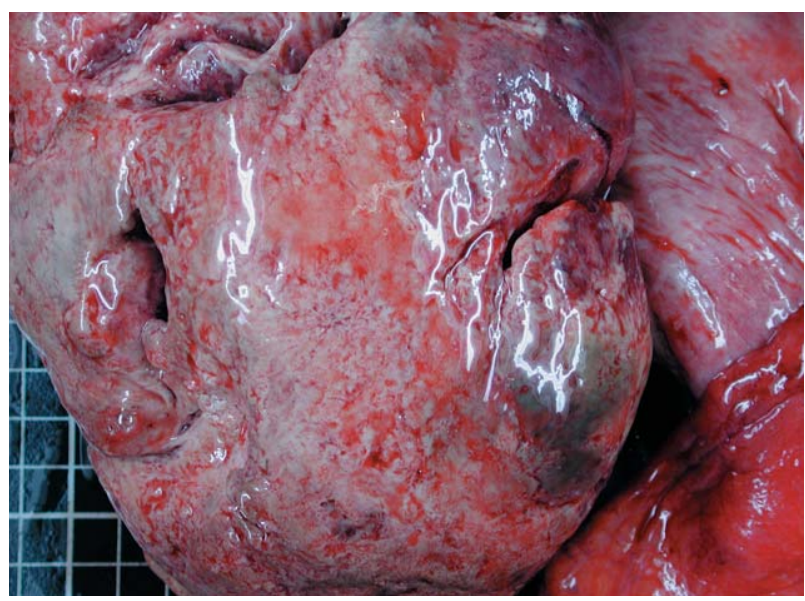

FIGURA 4 